\title{
A DIPLOMACIA BRASILEIRA DIANTE DA IMIGRAÇÃO JAPONESA $(1897-1942)$
}

Esta comunicação tem como objetivo demonstrar que a análise da documentação diplomática sob a guarda do Arquivo Histórico do Itamaraty, entre 1897 e 1942, nos permite delinear hipóteses a respeito do imaginário oficial sobre o Japão e os japoneses no período. Esse recorte temporal foi por mim estabelecido tendo como balizas o ano da abertura da Legação do Brasil em Tóquio e o rompimento das relações diplomáticas entre o Brasil e o Japão no contexto da Segunda Guerra Mundial.

O levantamento dos ofícios, telegramas e despachos emitidos e recebidos pelo Ministério das Relações Exteriores nos fornece subsídios para estabelecer os movimentos da nossa diplomacia no sentido de buscar influir no "jogo de xadrez" político em que estava inserida a questão imigratória japonesa para o Brasil. Tal influência estava presente não somente nos momentos de maior impacto sobre o tema, como no episódio referente às emendas antinipônicas apresentadas durante a Constituinte de 1934, mas, também, durante a "normalidade" das relações entre as duas nações.

Optei em não me aprofundar na abordagem a respeito da elaboração da referida Carta Constitucional de 1934, e o papel do Itamaraty nos debates, uma vez que há trabalhos acadêmicos que já exploraram essa vertente anteriormente. ${ }^{2}$

1. Doutora em História Social pela FFLCH - USP, pesquisadora do PROIN-USP e LEEC-USP.

2. Cito o livro de Valdemar Carneiro Leão Neto, $A$ Crise da Imigração Japonesa no Brasil (1930-1934): Contornos Diplomáticos (1989), a dissertação de mestrado de Flávio Venâncio Luizetto, Os Constituintes em Face da Imigração, defendida na FFLCH-USP em 1975 e meu livro O Perigo Amarelo: Imagens do Mito, Realidade do Preconceito (2008). 
Contudo, apontarei que não foi apenas nesse caso que a nossa diplomacia foi atuante de forma decisiva.

É importante observar primeiramente, que embora o ideário a respeito do Japão estivesse presente antes mesmo da chegada dos 781 pioneiros do Kasato Maru, em 18 de junho de 1908, o início efetivo da imigração japonesa evidenciaria e consolidaria as imagens e os estereótipos em torno desses estrangeiros. Em que consistiam essas imagens?

Na virada do século XIX para o XX, o pouco se sabia sobre o Japão era através da literatura de viagens produzidas pelos europeus que visitavam o Império do Sol Nascente após a sua reabertura ao Ocidente, em 1854. As referências em torno da misteriosa terra das cerejeiras, das gueixas e samurais fomentaram o fenômeno conhecido como Japonismo. $\mathrm{O}$ arquipélago japonês surgia como um território exótico e preservado, sem paralelo no mundo ocidental.

A febre pelo Japão era, portanto, incitada pelos relatos de viajantes ou, ainda, através da atividade de colecionadores, atraídos pelas estampas, lacas, esculturas, porcelanas, biombos e outros objetos tipicamente nipônicos. Além da face original do império, outras circunstâncias configuraram o imaginário nacional sobre o Japão: o seu isolamento, que proporcionara a homogeneidade política, cultural e racial dos japoneses e, tambem, a admiração também rápida modernização japonesa, além das vitórias militares japonesas sobre a China (1895) e, principalmente, sobre a Rússia, em 1905. ${ }^{3}$

Efetivamente, a elite brasileira visualizava o exemplo japonês enquanto modelo para o regime republicano recentemente instaurado. Um modelo contraditório e ambíguo, especialmente quando se aventava a hipótese da mão de obra japonesa na lavoura cafeeira paulista. Tal ambigüidade se devia, justamente, às teorias raciais em voga na Europa na segunda metade do século XIX, que obteve larga aceitação entre a nossa intelligentsia. Havia, por parte dos detentores do poder político, a defesa do progressivo branqueamento da população, através do incentivo à imigração européia. A "depuração" da raça brasileira era encarada como condição sine qua non para que o Brasil ingressasse o rol das nações modernas e desenvolvidas.

Assim, a definição dos grupos étnicos que poderiam contribuir para a cultura nacional foi tido pela nossa elite como fundamental para o papel que o Brasil assumiria frente ao chamado mundo civilizado. O "pensar a Nação" em concepções raciais se originava da própria configuração da república brasileira, regida por instituições liberais, importadas dos EUA e da Europa, e a manutenção dos valores oligárquicos e o poder

3. Celina Kuniyoshi. Imagens do Japão: uma utopia de viajantes. São Paulo: Estação Liberdade: FAPESP, 1998, p.9. 
nas mãos da elite agrária, conforme nos demonstram os estudos de Elias Tomé Saliba ${ }^{4} \mathrm{e}$ Roberto Schwarz .

Logo, a hipótese de importação de trabalhadores japoneses pressupunha a inserção de sangue mongólico em um caldeirão racial tido como já comprometido por raças "inferiores": a negra e indígena. Com a abolição da escravatura, em 1888, e a exclusão do negro do sistema de trabalho livre, a oligarquia cafeeira passou a incentivar a imigração européia, particularmente, os colonos italianos. Contudo, a instabilidade verificada na permanência desses trabalhadores nas fazendas e as revoltas motivadas pela exploração e pelos maus tratos, motivaram a nossa elite a buscar alternativas, como o japonês, enquanto imigrante mais dócil e cordato.

Dentro desse novo contexto, havia a intenção por parte do governo brasileiro em estabelecer tratados com a China e o Japão, particularmente com este último, alvo de admiração política pelo seu dinâmico progresso em poucas décadas. O primeiro passo nesse sentido foi dado com a negociação entre os dois países de um tratado de amizade e comércio em 1892. No entanto, a exigência do Japão em firmá-lo em pé de igualdade, adiou a sua assinatura até 5 de novembro de 1895, quando em Paris foi celebrado o Tratado de Amizade, Comércio e Navegação.

As instruções encaminhadas pelo Itamaraty ao Ministro Residente em Paris, Gabriel de Toledo Piza, resumiam-se a solicitar a eliminação do texto a menção de que os cônsules brasileiros no Japão seriam nomeados a fim da conveniência do comércio. O Ministério das Relações Exteriores estabelecia então, diretamente, que naquele momento interessava discutir com o Japão o assunto imigração. ${ }^{6}$ Posteriormente, em agosto de 1897 foi instalada a Legação Japonesa no Rio de Janeiro e, no mês seguinte, foi inaugurada a Legação Brasileira em Tóquio, cujo primeiro titular foi Henrique Carlos Ribeiro Lisboa.

Embora, a historiografia ${ }^{7}$ demonstre que não havia maior interesse japonês no envio de seus súditos ao nosso país, até a restrição imposta pelos Estados Unidos aos seus nacionais, em 1907, a documentação diplomática sob a guarda do Arquivo Histórico do Itamaraty $(\mathrm{RJ})$ comprova a resistência oficial brasileira aos nipônicos.

4. Raizes do Riso: A Representação Humoristica na História Brasileira da Belle Époque aos Primeiros Tempos do Rádio. São Paulo: Companhia das Letras, 2002.

5. Que Horas São? São Paulo, Companhia das Letras, 1997.

6. Idem, p.21.

7. Dentre os estudos que abordam essa questão cito o de Rogério Dezem. Matizes do "Amarelo": A Gênese dos Discursos sobre os Orientais no Brasil (1878-1908). São Paulo, Associação Editorial Humanitas, 2005 e de Célia Sakurai. "Imigração Japonesa para o Brasil: Um Exemplo de Imigração Tutelada (1908-1941)" In: Boris Fausto (org.). Fazer a América, $2^{\circ}$ ed. São Paulo: Editora da Universidade de São Paulo, 2000. 
Percebemos, através da análise das correspondências trocadas entre o Itamaraty e a representação diplomática em Tóquio que, além da questão racial, havia o receio de que os imigrantes dessa origem servissem como fatores de desordem política e econômica no país de adoção. Os contrários à imigração japonesa se reportavam ao exemplo norte-americano, afirmando que os nipônicos instalados na Califórnia, eram causa de discórdia, por se contentarem com salários menores em relação aos brancos e serem suspeitos de infiltração na sociedade norte-americana, a fim de preparar a invasão militar japonesa. Em síntese: se o Japão era um espelho como Nação, não o era enquanto fornecedor de imigrantes.

Nesses primeiros anos das relações Brasil-Japão, a atuação do Itamaraty neste contexto pode ser exemplificada a partir da postura de dois diplomatas brasileiros, que se destacaram em seu posicionamento antinipônico e no tom pouco comum que destoava da costumeira linguagem diplomática: Manoel de Oliveira Lima, Encarregado de Negócios na Legação entre 22 de junho de 1901 e 10 de maio de 1903, e Luis Guimarães, Encarregado de Negócios, entre 1906 e 1909.

Oliveira Lima, em sua correspondência com o Itamaraty, preocupou-se em alertar sobre a inconveniência da introdução de japoneses no Brasil. Alegava para tanto, razões políticas e raciais. Durante a sua permanência em Tóquio, forneceu os fundamentos para os seus temores através de envio de fragmentos de jornais japoneses relatando os problemas enfrentados pelos imigrantes nipônicos nos países que os recebiam, prevendo que o mesmo ocorreria no nosso país. Como exemplo, citamos o oficio datado de 26 de julho de $1907 \mathrm{em}$ que encaminhava um artigo publicado no Japan Mail, diário em língua inglesa publicado em Yokohama, que relatava os sofrimentos vivenciados pelos japoneses na Nova Caledônia. Tal fato evidenciava, na opinião do diplomata, os motivos que levavam o governo de Tóquio a fiscalizar a saída de seus súditos e o seu status no exterior, exigindo para eles a mesma consideração dada aos demais imigrantes provenientes dos países cultos da Europa e da América. Em síntese: a excessiva suscetibilidade do governo japonês recomendava uma maior ponderação por parte dos países necessitados de braços, caso do Brasil. ${ }^{8}$

As advertências vindas da Legação no Japão sobem de tom quando esta recebe a notícia de que o governo paulista havia firmado um contrato com o comerciante Marcial Sanz Elorz, que previa a vinda de 600 famílias japonesas. Francisco de Paula Rodrigues Alves, então Presidente de São Paulo, solicitou ao Itamaraty que determinasse ao seu encarregado de negócios no Japão que facilitasse as negociações de Elorz junto às autoridades japonesas. Oliveira Lima, em ofício de 15 de setembro de 1901, emitiu um parecer em que qualificava

8. Oficio $n^{\sim} 7$ de Manoel Oliveira Lima, Encarregado de Negócios do Brasil em Tóquio, para Olyntho de Magalhães, Ministro de Estado das Relações Exteriores. Legação dos Estados Unidos do Brasil. Tóquio, 05/09/1901. AHI/RJ. 
de "indesejável” essa imigração. Citava como motivos, além da incorporação no organismo nacional de elemento inferior racialmente, de costumes, moral e psicologia distantes da raça ariana, o distanciamento técnico dos agricultores japoneses com relação ao modo de trabalho nas grandes lavouras.

Entretanto, o peso maior das suas críticas recaía na "raça japonesa" que traria em si suas características intrínsecas inalteradas, à despeito do verniz de civilização de que o Império do Sol Nascente se recobriu para implementar o seu desenvolvimento econômico. Em sua opinião, o japonês - assim como o chinês - não se assimilava às nações que o recebia, ou seja, buscava somente acumular algum capital para retornar o mais rapidamente possível às "suas montanhas" As dificuldades em se adaptarem ao Brasil fariam que os nipônicos certamente provocassem os conflitos verificados na Nova Caledônia. ${ }^{9}$

A aquiescência do Itamaraty ao posicionamento de Oliveira Lima pode ser verificada na observação registrada na primeira página do ofício: uma cópia deste documento foi remetida ao governo paulista em 16 de novembro de 1901. No entanto, Oliveira Lima avaliava que os negócios de Elorz não foram bem sucedidos, tanto que o mesmo solicitava, via Legação de Tóquio, a modificação de termos do contrato, possibilitando a substituição de japoneses por chineses. Essa mudança foi avaliada pelo diplomata como positiva, uma vez que considerava os chins "mais laboriosos e acomodados" do que os nipônicos. ${ }^{10}$

Numa postura consideravelmente belicosa, Luis Guimarães condenava em oficio dirigido à Carlos Botelho, Secretário de Agricultura de São Paulo, a tratativa de importação de trabalhadores japoneses para o Brasil, através de contrato firmado entre Ryu Mizuno e o governo Paulista. ${ }^{11}$ A sua gestão à frente da representação diplomática no Japão reiterava a intolerância em relação à imigração japonesa expressada por Manoel de Oliveira Lima. Entre outubro de 1906 e junho de 1908, Luis Guimarães, através de ofícios reservados, emitia a sua opinião contrária ao projeto paulista. Contudo, Guimarães não se limitava a externar a sua discordância, mas solicitou em diversos momentos que o Itamaraty interviesse no sentido de evitar a sua concretização.

Conceitos como "o japonês não se assimilava aos costumes de seu novo país, e ainda procurava impor os seus; o Japão era uma potência ao qual se precisava prestar contas;

9. Oficio $n^{\circ} 1$ (reservado) de Manoel Oliveira Lima, Encarregado de Negócios do Brasil em Tóquio, para Olyntho de Magalhães, Ministro de Estado das Relações Exteriores. Legação dos Estados Unidos do Brasil. Tóquio, 15/09/1901.AHI/RJ.

10. Oficio $s / n^{\circ}$ de Manoel Oliveira Lima, Encarregado de Negócios do Brasil em Tóquio, para Olyntho de Magalhães, Ministro de Estado das Relaçães Exteriores. Legação dos Estados Unidos do Brasil. Tóquio, $12 / 04 / 1902$. AHI/RJ.

11. Oficio $s / n^{\circ}$ (reservado) de Luís Guimarães, Encarregado de Negócios do Brasil em Tóquio, para Carlos Botelho, Secretário de Agricultura do Estado de São Paulo. Legação dos Estados Unidos do Brasil. Tóquio, 22/06/1908. AHI/RJ. 
o colono japonês se queixava diariamente, incomodando os governos que o hospedavam; o povo japonês se julgava o mais poderoso e perfeito da Terra, o que poderia representar um perigo político para o futuro ${ }^{12}$; o japonês desalojaria o trabalhador nacional e estrangeiro, por se contentar com qualquer miséria", resumem o pensamento de Guimarães, que profetizava uma futura guerra entre os EUA e o Japão por causa de São Francisco, Havaí e Filipinas. Em síntese: a introdução de japoneses seria uma "verdadeira calamidade"13, era como ter um "inimigo dentro de casa"14

Além das questões político-sociais, Luis Guimarães acrescentava as de ordem eugênica: o sangue mongólico e a fealdade da raça japonesa comprometeriam a formação da raça brasileira. $\mathrm{O}$ cruzamento com uma raça heterogênea e inferior, resultaria em "degeneração, o abastardamento, o hibridismo"15 e contato com uma "gente soberba, agressiva e chicaneira", que vinha exigindo do seu país uma reação à altura para as humilhações sofridas pelos nipônicos na costa oeste norte-americana.

A intervenção de Guimarães no sentido da diplomacia brasileira realizar uma "discreta oposição" aos planos paulistas, resultou em uma troca de correspondência entre o Itamaraty, a Legação do Brasil em Tóquio e Carlos Botelho. Este encaminhou um despacho à Guimarães, em 25 de abril de 1908, em que estava anexo o contrato firmado com a Companhia Imperial de Emigração. Através deste documento, Botelho informava ao Ministério das Relações Exteriores que São Paulo não pretendia implantar a colonização japonesa, mas o ensaio de braços para a lavoura cafeeira tendo em vista os embaraços oferecidos pelas nações européias para a saída de seus nacionais. ${ }^{16}$

Entretanto, Guimarães recordava que apenas o Brasil aceitava os japoneses quando os demais países lhes fechavam a porta e advertia: "Os japoneses serão mais dia ou menos dia causa de grandes discórdias no nosso pais. O japonês,

12. Oficio $n^{\iota} 4$ (Reservado) de Luis Guimarães, Encarregado de Negócios do Brasil em Tóquio, para o Barão de Rio Branco, Ministro de Estado das Relações Exteriores. Legação dos Estados Unidos do Brasil. Tóquio, 04/12/1906. AHURJ.

13. Oficio $n^{\circ} 4$ (Reservado) de Luis Guimarães, Encarregado de Negócios do Brasil em Tóquio, para o Barão de Rio Branco. Ministro de Estado das Relações Exteriores. Legação dos Estados Unidos do Brasil. Tóquio, 23/09/1907. AHI/RJ.

14. Oficio $n^{0} 5$ (Reservado) de Luis Guimarães, Encarregado de Negócios do Brasil em Tóquio, para o Barão de Rio Branco, Ministro de Estado das Relações Exteriores. Legação dos Estados Unidos do Brasil. Tóquio, 23/09/1907. AHI/RJ.

15. Resumo do oficio $\mathrm{n}^{\circ} 4$ (reservado) de 4 de dezembro de 1906. Legação dos Estados Unidos do Brasil. Tóquio, 04/12/1906. (documento mimeografado). AHI/RJ.

16. Oficio $s / n^{\iota}$ (reservado) de Luis Guimarães, Encarregado de Negócios do Brasil em Tóquio, para Carlos Botelho, Secretário de Agricultura do Estado de São Paulo. Legação dos Estados Unidos do Brasil. Tóquio, 22/06/1908. AHI/RJ. 
Senhor Ministro, permanece toda a vida japonês; é espião de nascença, é nosso inimigo pelo sangue, é orgulhoso até a morte, é semeador de todo tipo de discórdias"17 18

A contrariedade do Itamaraty, fato comprovado pelo envio de cópias dos oficios de Guimarães ao governo paulista e ao Ministério da Agricultura, não foi o bastante para frustrar a inauguração da corrente imigratória japonesa no Brasil. Contudo, ela principiou sob uma atmosfera de debate e polêmica.

Portanto, pode-se afirmar que a postura do Itamaraty esteve diretamente associada às questões raciais e políticas que tinha como protagonista o Império do Sol Nascente. Tanto que da primeira década do século XX até o início do ano de 1942, quando ocorre o rompimento das relações diplomáticas entre os dois países, a nossa chancelaria acompanhava com atenção as ações imperialistas japonesas na Ásia.

Os aspectos de maior interesse, que se depreendem dos oficios enviados pelos nossos diplomatas em Tóquio até o final da década de 1920, se referiam aos conflitos verificados entre os imigrantes japoneses na Califórnia e os trabalhadores brancos. São recorrentes os relatos sobre as reações da opinião pública japonesa e do governo japonês contra as pretensões do Congresso Estadual da Califórnia em debater projetos de lei que visavam excluir crianças japonesas de suas escolas públicas ou impedir que cidadãos nipônicos adquirissem bens imóveis no Estado. Gustavo de Vianna Kelsch, que substituíra Manoel Carlos Gonçalves Pereira, Enviado Especial e Ministro Plenipotenciário em Tóquio, no comando da Legação especulava, em abril de 1913, que a insatisfação japonesa poderia levar a um conflito armado entre os EUA e o Japão ${ }^{19}$

Entretanto, a despeito das preocupações suscitadas pela suposta "infiltração japonesa", o Império do Sol Nascente era uma potência de peso e o mesmo Kelsch, sob ordens do Itamaraty, negociava um tratado de arbitramento com o Império do Sol Nascente nesse mesmo ano de 1913. Em oficio enviado ao Ministro das Relações Exteriores, Francisco Régis de Oliveira informava que, conforme as instruções recebidas, consultaria "habilmente" o Ministério dos Negócios Estrangeiros (Gaimusho) sobre o assunto, observando a possibilidade do atual governo japonês ter opinião diversa sobre $o$ assunto em relação ao anterior em $1911 .{ }^{20}$

17. A grafia nas citações de época foram atualizadas.

18. Idem.

19. Oficio $n^{\circ} 2$ de Gustavo de Vianna Kelsch, Encarregado de Negócios do Brasil, para Lauro Severiano Muller, Ministro de Estado das Relações Exteriores. Legação dos Estados Unidos do Brasil. Tóquio, 20/04/1913.

20. Oficio $n^{\circ} 3$ (reservado) de Gustavo de Vianna Kelsch, Encarregado de Negócios do Brasil, para Francisco Régis de Oliveira, Ministro de Estado das Relações Exteriores. Legação dos Estados Unidos do Brasil. Tóquio, 29/08/1913. 
Mal sucedido, devido a falta de interesse por parte do governo japonês em estabelecer esse tratado com o Brasil, Kelsch desabafava afirmando que o governo brasileiro vinha fazendo aos japoneses todas as concessões, enfrentando por vezes "sérias oposições" Exemplificava alguns exemplos do que considerava "má vontade japonesa": "se pedimos o embarque de alguns de nossos oficiais de marinha em navios da esquadra japonesa, negam-nos. Se queremos a criação de um Consulado honorário no Pará, negam-nos. Se propomos a celebração de um tratado de arbitramento, adiam a matéria indefinidamente". ${ }^{21}$ Sugeria retaliar tal atitude com a mudança da Legação para Pequim e negar qualquer concessão futura à imigração japonesa. Nesse quesito, afirmava, se unia a todos os antecessores que se posicionaram contra essa corrente imigratória.

Efetivamente, verifica-se que a amostragem de documentos que citamos não reflete uma atitude isolada de alguns diplomatas, mas tinham a ressonância e a concordância do Itamaraty, que através de despachos endossava os conceitos antinipônicos expressos pelos seus representantes no Japão. Despachos confidenciais reafirmavam que a imigração japonesa não convinha ao Brasil, alegando-se que os japoneses não se assimilavam "para onde quer que vão, com os habitantes do país", ${ }^{22}$

Ressaltamos que identificamos nessas manifestações um caráter de persistência, uma vez que elas se repetem em diferentes períodos. Ainda mais importante: os juízos de valor emitidos pela Chancelaria brasileira não ficavam ali restritos, mas serviam como instrumentos que objetivavam persuadir os estados que recebiam os imigrantes japoneses a alterarem sua política imigratória. Essa situação pode ser exemplificada na resposta do Itamaraty à solicitação de Epaminondas Leite Chermont, que assumira como Enviado Extraordinário e Ministro Plenipotenciário do Brasil no Japão em 21 de setembro de 1915.

Em ofício reservado de 12 de dezembro de 1916, Chermont detectava que a imprensa japonesa servia ao governo japonês como meio de propaganda para estimular a emigração japonesa para o Brasil, sobre a qual sempre tivera restrições. Afirmava que seria adequado por parte do Ministério das Relações Exteriores reunir todos os oficios emitidos desde 1901 pela Legação sobre a imigração japonesa para enviá-los ao governo paulista, a fim de não precisar repetir "o que foi dito e redito por esta Legação em várias épocas...". Afirma que com isso não tem outra intenção senão "defender os interesses futuros do Brasil francamente ameaçados" ${ }^{23}$ Em resposta, Gregório Pecegueiro, Diretor Geral do Itamaraty,

21. Idem.

22. Despacho $n^{*} l$ (confidencial) de Francisco Régis de Oliveira, Ministro de Estado das Relaçöes Exteriores, para José Francisco de Barros Pimentel, Encarregado de Negócios do Brasil em Tóquio. Ministério das Relações Exteriores. Rio de Janeiro, 22/01/1914.

23. Oficio n" 1 (reservado) de Epaminondas Leite Chermont, Ministro Plenipotenciário do Brasil, para Lauro Severiano Muller, Ministro de Estado das Relaçōes Exteriores. Seção dos Negócios Econômicos e Consulares da Europa, Ásia, Africa e Oceania. Legação dos Estados Unidos do Brasil. Tóquio, 12/12/1916. 
informava ao representante em Tóquio, que o Ministro Lauro Muller já havia solicitado a reunião de todos os oficios sobre o tema e em todos havia informações desfavoráveis sobre a emigração japonesa e se apontavam os seus inconvenientes no declarado intuito de refrear a entrada de japoneses. Acrescentava que Minas Gerais e São Paulo haviam feito contratos com os japoneses, fatos que foram informados ao Ministério da Agricultura. ${ }^{24}$

Com o fim do subsídio paulista à imigração japonesa, em 1922, e a promulgação da Lei da Origem Nacional pelo Congresso norte-americano, em 1924, que vedava definitivamente a imigração japonesa para os EUA, o Japão assumiu o encaminhamento de seus súditos para o Brasil. Diante dessa nova configuração da imigração japonesa, a representação brasileira no Japão, já elevada à categoria de Embaixada, acompanhava o tema, que sempre fora desde o início das relações bi-laterais, o principal ponto de interesse comum no relacionamento entre os dois países.

A suspeita da intelligentsia brasileira, acompanhada pela nossa diplomacia, de que a imigração japonesa atendia a fins políticos estava associada com o fato de que a saída de nipônicos pobres da pátria iniciou-se por razões capitalistas. O desenvolvimento tardio do capitalismo japonês teve início dentro do contexto de competição dos países ocidentais pela implantação de colônias no exterior e, por esta razão, assumiu características imperialistas de aumento do poder econômico pela expansão territorial. ${ }^{25}$ Tal situação era associada à aquisição de terras no Brasil por parte das empresas japonesas, onde foram instalados núcleos coloniais como as administradas pela BRATAC e pela KKKK.

Uma nova etapa da imigração japonesa para o Brasil se descortinava, mas não houve alteração na visão da nossa diplomacia. $O$ teor dos ofícios encaminhados pela embaixada brasileira comprova que os ânimos antinipônicos permaneciam, sendo as razões alegadas as mesmas: problema de assimilação do japonês, sua inferioridade racial e o perigo político representado pelos imigrantes localizados em pontos estratégicos do território nacional. Nesse sentido, a documentação oficial expressa as inquietações da nossa elite com relação a aquisição de lotes de terras para implantação de colônias agrícolas japonesas no nosso país. É o caso da doação de um milhão de hectares de terras por parte do governo da Pará, e a instalação de uma colônia nessa região amazônica em 1929. O conceito de "infiltração japonesa" novamente entrava na pauta do dia.

Os diplomatas acompanhavam com preocupação esses movimentos, que em diferentes ocasiões, interpretavam não como imigração japonesa, mas expansão

24. Despacho de Gregório Pecegueiro. Diretoria Geral/Secretaria de Estado dos Negócios Exteriores. Rio de Janeiro, 23/07/1917.

25. Chiyoko Mita. Bastos: Uma Comunidade Étnica Japonesa no Brasil. São Paulo: Humanitas/FFLCH/USP, 1999 , p. 96. 
imperialista motivada pela superpopulação e pobreza de recursos naturais. A década de 1930 representou, além de um expressivo aumento da entrada de japoneses, a atenção por parte de nossas autoridades nas campanhas militares japonesas na Ásia. O Incidente da Manchúria, em 1931, e o estabelecimento de um Estado títere na região, Manchukuo, em 18 de fevereiro de 1932, são acontecimentos presentes na documentação arquivada no Arquivo Histórico do Itamaraty com freqüência, até ser suplantada pelas notícias sobre a repercussão das emendas antinipônicas apresentadas na Assembléia Nacional Constituinte instalada em 1933.

Em concordância com o momento político vivenciado pelo Brasil, a ascensão de Getúlio Vargas com a Revolução de 1930 e a vertente nacionalista e xenófoba de seu governo, as emendas apresentadas pela corrente antinipônica produziram um efeito diferenciado, em relação a postura adotada até então pelo Itamaraty. Diante da possibilidade concreta de conflitos diplomáticos entre o Brasil e o Japão, iniciou-se uma negociação entre os Ministérios das Relações Exteriores de ambos os países e as forças políticas na Assembléia a fim de se evitar a aprovação das emendas diretamente discriminatórias.

Entretanto, a crise verificada nesse período não representou uma mudança de rumo na diplomacia brasileira. Os oficios encaminhados pela representação brasileira nos anos seguintes refletiam os acontecimentos que levariam ao início da Segunda Guerra Mundial e o rompimento das relações diplomáticas entre o Brasil e o Japão, em 29 de janeiro de 1942. Os informes que se destinavam ao Itamaraty traçavam as ações imperialistas japonesas e especulavam sobre a lealdade dos nipônicos - transformados em súditos do Eixo - instalados no nosso país à sua pátria e o perigo que representavam à segurança nacional.

A pesquisa na documentação diplomática nos fornece dados importantes para avaliação desse período, que representou a interrupção do relacionamento entre os dois países até 1952. O ânimo presente nesses momentos finais pode ser verificado em um relato preciso e interno do que ocorrera em 2 de fevereiro de 1942, dia em que o embaixador F. de CastelloBranco Clark comunicaria o rompimento das relações diplomáticas. A embaixada fora cercada e ocupada pelo exército e pela polícia. $O$ embaixador relata, em memorando, que a partir deste instante ficara incomunicável, juntamente com os funcionários da Embaixada. $\mathrm{O}$ abalo psicológico provocado pela atitude, classificada de atos "abruptos, ríspidos e deselegantes" do govemo japonês, teria mesmo causado a morte da esposa do primeiro secretário da embaixada, Nabuco de $\mathrm{Abreu}^{26}$. Essa ocupação, que durara mais de dois meses, simboliza e encerra a fase delicada da história das relações diplomáticas entre o Brasil e o Japão.

26. Memorando (cópia) de F. de Castello-Branco Clark, embaixador do Brasil, para L. Esteves Fernandes, Ministro de Portugal no Japão. Embaixada dos Estados Unidos do Brasil. Tóquio, 14/03/1942. (46-2-10). (anexo $n^{\circ} 1$ ao of. $s / n^{\circ}$ de 22/08/1942). 
Fase em que a introdução de imigrantes japoneses em uma terra de cultura e costumes completamente diferentes, suscitara estranhamento e desconfiança de ambos os lados. Não foi possível nesta breve comunicação, estabelecermos em detalhes os percursos do antiniponismo oficial, senão apontarmos alguns pontos. No entanto, as atuais boas relações entre o Brasil e o Japão - uma realidade inegável - foram construídas sobre uma base em que não estiveram ausentes os conflitos, a xenofobia e o racismo. E o mais importante: a atuação efetiva do Itamaraty na construção da imagem estigmatizada do imigrante japonês, encarado como o outro, a quem se devia evitar, mediante uma "discreta oposição" às pretensões japonesas de enviar o seu excedente populacional ao paraíso da democracia racial.

\section{Fontes}

Oficio $n^{\circ} 7$ de Manoel Oliveira Lima, Encarregado de Negócios do Brasil em Tóquio, para Olyntho de Magalhães, Ministro de Estado das Relações Exteriores. Legação dos Estados Unidos do Brasil. Tóquio, 05/09/1901. AHI/RJ.

Oficio $n^{\circ} 1$ (reservado) de Manoel Oliveira Lima, Encarregado de Negócios do Brasil em Tóquio, para Olyntho de Magalhães, Ministro de Estado das Relações Exteriores. Legação dos Estados Unidos do Brasil. Tóquio, 15/09/1901.AHI/RJ.

Oficio $s / n^{\circ}$ de Manoel Oliveira Lima, Encarregado de Negócios do Brasil em Tóquio, para Olyntho de Magalhães, Ministro de Estado das Relações Exteriores. Legação dos Estados Unidos do Brasil. Tóquio, 12/04/1902. AHI/RJ.

Oficio $s / n^{\circ}$ (reservado) de Luís Guimarães, Encarregado de Negócios do Brasil em Tóquio, para Carlos Botelho, Secretário de Agricultura do Estado de São Paulo. Legação dos Estados Unidos do Brasil. Tóquio, 22/06/1908. AHI/RJ.

Oficio $n^{\circ} 4$ (Reservado) de Luis Guimarães, Encarregado de Negócios do Brasil em Tóquio, para o Barão de Rio Branco, Ministro de Estado das Relações Exteriores. Legação dos Estados Unidos do Brasil. Tóquio, 04/12/1906. AHI/RJ.

Oficio $n^{\circ} 4$ (Reservado) de Luis Guimarães, Encarregado de Negócios do Brasil em Tóquio, para o Barão de Rio Branco, Ministro de Estado das Relações Exteriores. Legação dos Estados Unidos do Brasil. Tóquio, 23/09/1907. AHI/RJ.

Oficio $n^{\circ} 5$ (Reservado) de Luis Guimarães, Encarregado de Negócios do Brasil em Tóquio, para o Barão de Rio Branco, Ministro de Estado das Relações Exteriores. Legação dos Estados Unidos do Brasil. Tóquio, 23/09/1907. AHL/RJ.

Resumo do ofício n ${ }^{\circ} 4$ (reservado) de 4 de dezembro de 1906. Legação dos Estados Unidos do Brasil. Tóquio, 04/12/1906. (documento mimeografado). AHI/RJ. 
Oficio s/n (reservado) de Luis Guimarães, Encarregado de Negócios do Brasil em Tóquio, para Carlos Botelho, Secretário de Agricultura do Estado de São Paulo. Legação dos Estados Unidos do Brasil. Tóquio, 22/06/1908. AHI/RJ.

Oficio $n^{\circ} 2$ de Gustavo de Vianna Kelsch, Encarregado de Negócios do Brasil, para Lauro Severiano Muller, Ministro de Estado das Relações Exteriores. Legação dos Estados Unidos do Brasil. Tóquio, 20/04/1913.

Oficio $n^{\circ} 3$ (reservado) de Gustavo de Vianna Kelsch, Encarregado de Negócios do Brasil, para Francisco Régis de Oliveira, Ministro de Estado das Relações Exteriores. Legação dos Estados Unidos do Brasil. Tóquio, 29/08/1913.

Despacho $n^{\circ} 1$ (confidencial) de Francisco Régis de Oliveira, Ministro de Estado das Relações Exteriores, para José Francisco de Barros Pimentel, Encarregado de Negócios do Brasil em Tóquio. Ministério das Relações Exteriores. Rio de Janeiro, 22/01/1914.

Ofício $n^{o} 1$ (reservado) de Epaminondas Leite Chermont, Ministro Plenipotenciário do Brasil, para Lauro Severiano Muller, Ministro de Estado das Relações Exteriores. Seção dos Negócios Econômicos e Consulares da Europa, Ásia, África e Oceania. Legação dos Estados Unidos do Brasil. Tóquio, 12/12/1916.

Despacho de Gregório Pecegueiro. Diretoria Geral/Secretaria de Estado dos Negócios Exteriores. Rio de Janeiro, 23/07/1917.

Memorando (cópia) de F. de Castello-Branco Clark, embaixador do Brasil, para L. Esteves Fernandes, Ministro de Portugal no Japão. Embaixada dos Estados Unidos do Brasil. Tóquio, 14/03/1942. (46-2-10). (anexo $\mathrm{n}^{\mathrm{o}} 1$ ao of. $\mathrm{s} / \mathrm{n}^{\mathrm{o}} \mathrm{de} 22 / 08 / 1942$ ).

Bibliografia

DEZEM, Rogério. Matizes do "Amarelo": A Gênese dos Discursos Sobre os Orientais no Brasil (1878-1908). São Paulo, Associação Editorial Humanitas, 2005 .

KUNIYOSHI, Celina. Imagens do Japão: Uma Utopia de Viajantes. São Paulo: Estação Liberdade: FAPESP, 1998.

LUIZETTO, Flávio Venâncio. Os Constituintes em Face da Imigração. Dissertação de Mestrado em História, FFLCH-USP, 1975.

NETO, Waldemar Carneiro Leão. A Crise da Imigração Japonesa no Brasil (1930-1934): Contornos Diplomáticos. Brasilia: Fundação Alexandre de Gusmão, 1989. (Relações Internacionais; 10). 
SAKURAI, Célia. "Imigração Japonesa para o Brasil: Um Exemplo de Imigração Tutelada (1908-1941)". In: FAUSTO, Boris (org.). Fazer a América, $2^{\circ}$ ed. São Paulo: Editora da Universidade de São Paulo, 2000.

SALIBA, Elias Tomé. Raízes do Riso: A Representação Humorística na História Brasileira da Belle Époque aos Primeiros Tempos do Rádio. São Paulo: Companhia das Letras, 2002.

SCHWARZ, Roberto. Que Horas São? São Paulo, Companhia das Letras, 1997.

TAKEUCHI, Marcia Yumi. O Perigo Amarelo: Imagens do Mito, Realidade do Preconceito (1920-1945). São Paulo, Associação Editorial Humanitas, 2008. 